\title{
Dye Extraction and Cotton Dyeing from Peach Leaf
}

\author{
Lami Amanuel*, Demoze Adefris, Ehitnesh Ajaw, Netsanet Bekele and Atinkut Abinet \\ Department of Textile engineering, Wollo University, Ethiopia
}

Submission: August 07, 2019; Published: September 24, 2019

*Corresponding author: Lami Amanuel, Department of Textile engineering, Wollo University, Kombolcha institute of technology, P.0. Box 208, Ethiopia

\begin{abstract}
Peach leaf dye extracted by optimized Solvent extraction was used to dye cotton fabric. Optimization of Dye extraction and dyeing were done by varying one factor at a time keeping the others constant. The three different dyeing methods namely pre-mordanting, simultaneousmordanting and post-mordanting were used to dye the cotton fabrics. Color strength and shade depth of the dyed samples; i.e., the CIELAB $\left(L^{*}=50.29, a^{*}=3.83, b^{*}=37.18\right.$ and $K / S$ values of 1.9 were recorded from the dyed samples by using a spectrophotometer. Wash and rubbing fastness of the dyed samples were evaluated using Lin test colorfastness and annual rubbing fastness tester respectively. As per the findings of this research optimum peach leaf dye can be obtained if extraction carried out with MLR of 1:20 (Weight/Volume of peach leaf to water) at $80 \mathrm{oC}$ for 70minutes. Optimum Dyeing was recorded with MLR 1:25 (W/V of cotton fabric to water) at $900 \mathrm{C}$ for 45 minutes in neutral media using Copper sulfate as mordant. The dyed cotton fabric has excellent wash fastness and a moderate level of colorfastness to light and rubbing. .

Keywords: Dye extraction; Optimization; Mordanting; Color strength
\end{abstract}

\section{Introduction}

Textile dyeing industry uses an excessive amount of synthetic dyes to meet the required coloration of global consumption of textiles due to cheaper price, a wider range of bright shades and considerably improved fastness properties in competition to natural dyes $[1,2]$. But the production of synthetic dyes is dependent on petrochemical source [3] and some of these dyes contain carcinogenic amines. The application of such dyes causes serious health hazards and influences negatively eco-balance of nature [4] [3]. Natural dyes are dyes which are extracted from a natural source. It is mostly non-substantive applied on textiles with the help of mordents which is metallic salt having an affinity for both the coloring matter and the fiber [5]. Natural dyes are known for their use in the coloring of food substrate, leather as well as natural protein fibers like wool, silk, and cotton as major areas of application since pre-historic times. The use of non-allergic, non-toxic and eco-friendly natural dyes on textiles have become a matter of significant importance due to the increased environmental awareness to avoid some hazardous synthetic dyes for successful commercial use of natural dyes, the appropriate and standardized dyeing techniques need to be adopted without scarifying required quality of dyed textiles materials. Therefore; to obtain newer shades with acceptable color fastness [6] natural dyes come into existence.

Natural dyes are increasing continuously as their production and application do not require strong acids and alkalis $[2,7,8]$.
Natural dyes are believed that they have better biodegradability, have wide variety, less-toxic, non-carcinogenic, easily available and Renewable, eco-friend and generally higher compatibility with the environment; provide a wide range of beautiful shades with acceptable levels of colorfastness [8-10]. Natural dyes also offer functional benefits to the wearer and users of such textiles. Many of the natural dyes absorb in the ultraviolet region and therefore fabrics dyed with such dyes should offer good protection from ultraviolet light. Improvement in UV protection characteristics of natural cellulosic fibers after treatment with natural dyes has been reported by various researchers $[7,11,12]$. Many of the natural dye materials possess anti-microbial properties. Therefore, textiles dyed with such materials are also likely to show antimicrobial properties and the same has been reported by many researchers [12-14]. Natural dyes not only release medicinal properties but also improve the aesthetic value of the product and they are unique and eco-friendly $[8,15]$. The present study focuses on the extraction of dye from the peach leaf by optimizing the extraction and dyeing conditions.

\section{Materials and Methods}

\section{Materials}

Peach leaf collected from Northern Ethiopia (Dessie city), dried under shade hidden from direct sunlight and used to extract dye out of it. 


\section{Equipment}

The types of equipment used were digital electronic balance to measure the weight of materials and chemicals, Water bath, Hot air oven, grinding machine, thermometer beaker and launder meter paper, magnetic stirrer with hot plate, and measuring cylinders [16-18]. The Spectrophotometer will be used to evaluate color strength (K/S) and color values (CIEL*a*b*). For wash Fastness Testing Lin test machines and for rubbing fastness manual rubbing fastness tester machines are used.

\section{Chemicals}

As the extraction method used in this particular study was solvent extraction; Methanol is used as a solvent. Copper sulfate is the fixing agent used for fixing the dyes to cotton and the other auxiliary chemicals used were Sodium hydroxide and acetic acid. Acetic acid was used a PH stabilizer during sample dyeing.

\section{Methods}

\section{Preparation of peach leaf}

Peach leaves were collected manually from Peachtree (Figure 1a) and dried under shade hidden from direct sunlight and grounded (Figure $1 \mathrm{~b}$ ) by using grinder machine then sieving (Figure 1c) was carried out to remove particle sizes. For each extraction $10 \mathrm{gm}$ of peach leaf powder was used with distilled water to extract dye from the powder.

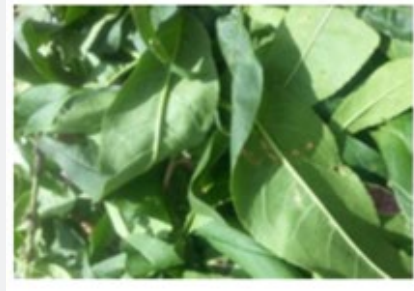

a) Peachtree

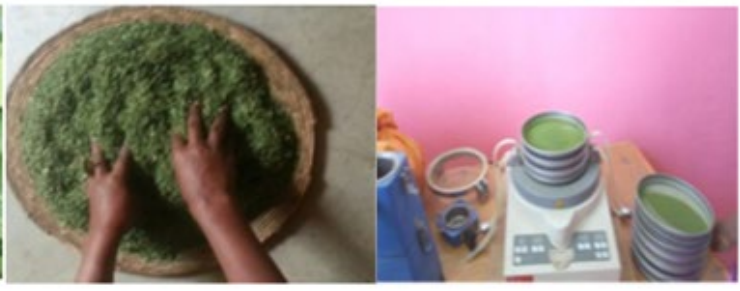

b) Grounded peach leaf

Figure 1: Preparation of lignocellulose sheet.

\section{Dye extraction and optimization of the extraction process}

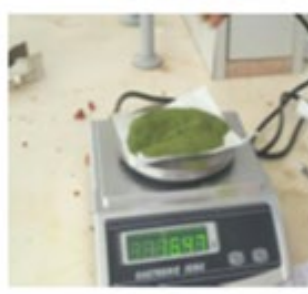

a) Weighing $10 \mathrm{gm}$ leaf peach powder

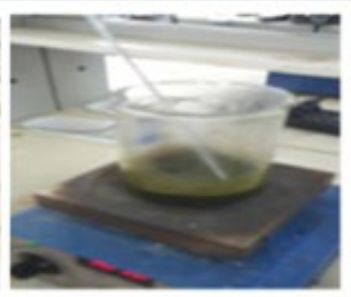

b) Mixing with water and methanol on the stove
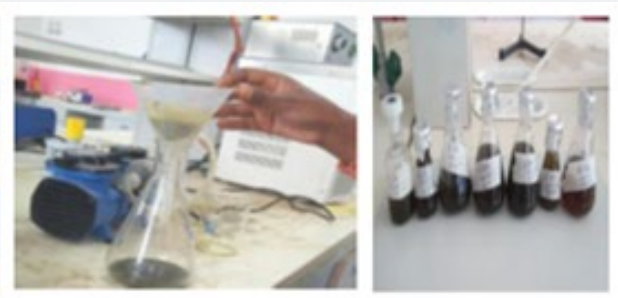

c) Filtering Extracted dye

d) Extracted dye preserved for dyeing

Figure 2: A photo showing the procedure of Dye extraction from peach leaf sheath powder photographed by the authors, 2019.

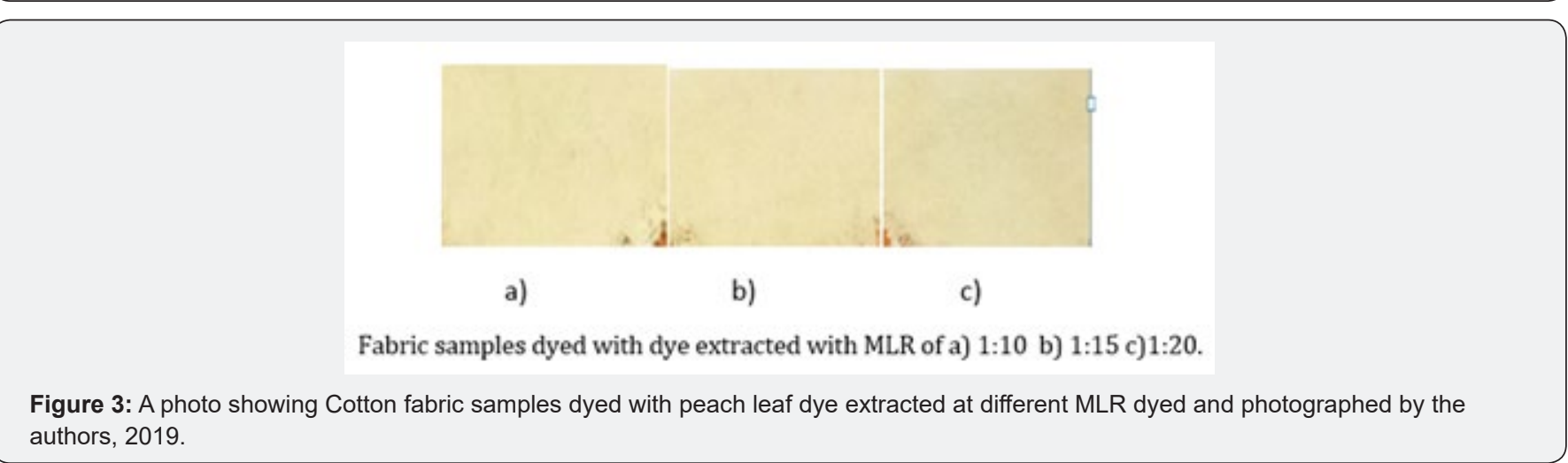

Considering Extraction MLR, extraction Temperature and Extraction time as variables which affect dye extraction quality dye extraction from 10gm peach leaf were optimized by varying only one variable at a time. From the four different 
dyes extracted at different MLR; the dye extracted with MLR of 1:20 has shown better color darkness [19-21]. With MLR of 1:5 it was impossible to filter dyestuff as the residue was thick and cannot pass through filter paper (Figures 2 \& 3). In the same manner, extraction temperature and extraction time were optimized. Optimization of extraction temperature was studied by extracting dyestuff with 1:20 MLR at three different temperatures $(60 \mathrm{oC}, 80 \mathrm{oC}$ and at boil temperature) keeping the other parameters constant. As it can be seen in Figure 4 among the dyed cotton fabrics (Figure 4a-4c) the dye extracted at $80 \mathrm{oC}$ has more dark shade. By extracting dyestuff $s$ at three different extraction times (40minutes, 60 minutes \& 70minutes) with
1:20 MLR at $80 \mathrm{oC}$ again three cotton fabric samples (Figure $5 a-5 c)$ were dyed to compare their shades. The cotton sample dyed with dye extracted within 70 minutes was found the darkest (Figure 5c). Finally, extraction was carried out at the optimized conditions (MLR of 1:20, extraction Time of 70 minutes and extraction Temperature of $800 \mathrm{C}$ ) and dyed a sample fabric to evaluate fabric color fastness and color strength [22-25]. For example or example To optimize MLR, Four Extractions were carried out with 4 different MLR ratios (with 1:5, 1:10, 1:15 and $1: 20 \mathrm{w} / \mathrm{v}$ ratio of peach leaf to water) keeping other parameters constant and cotton samples were dyed without mordent to evaluate its shade darkness.

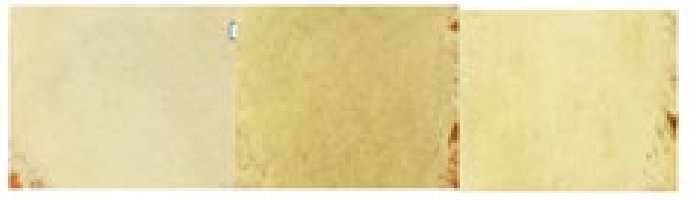

a) c)

Fabric sample dyed with Dye Extracted a) at boiling temperature b) at $80^{\circ} \mathrm{C}$ ) at $60^{\circ} \mathrm{C}$.

Figure 4: A photo showing cotton fabric samples dyed with peach leaf dye extracted at a different temperature, dyed and photographed by the authors, 2019.

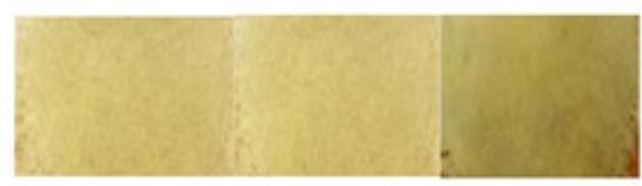

a)

b)

c)

Fabric sample dyed with Dye Extracted a) within 40 minutes b) within 60 minutes c) within 70 minutes

Figure 5: A photo showing cotton fabric samples dyed with peach leaf dye extracted with different extraction duration, dyed and photographed by the authors, 2019.

\section{Optimization of Dyeing conditions}

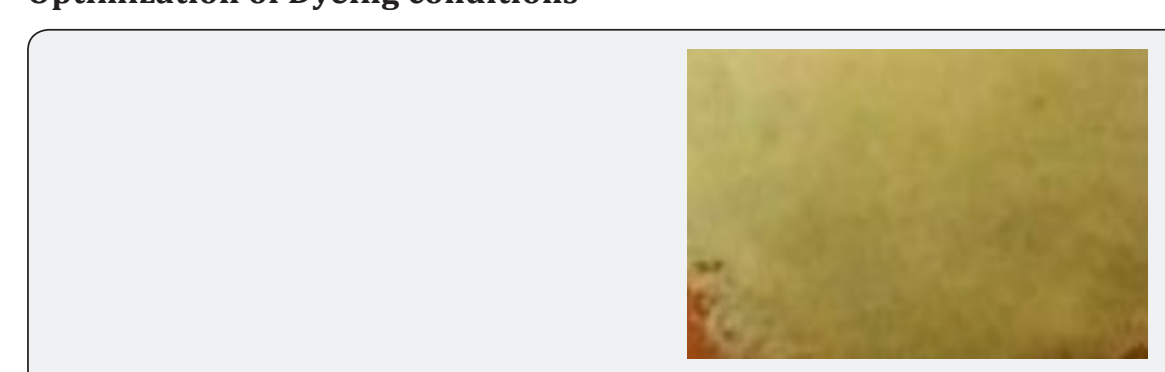

Figure 6: A photo of cotton fabric dyed with peach leaf dye extracted at optimum extraction conditions, dyed and Photographed by the authors, 2019.

Again, OFAT factorial design was employed by taking dyeing MLR, dyeing time, dyeing temperature, dyeing $\mathrm{Ph}$ and dyeing technique as variables to dye cotton samples in the presence or mordant and compare the quality of dyed samples in terms of wash fastness, rubbing fastness and color yield [26-30]. In
Figure 6 below the photograph of dyed fabric samples shows thee (3) fabric samples dyed by Simultaneous Dyeing at neutral $\mathrm{Ph}$ at three different MLR (1:25, 1:30, and 1:35) (Figure 6a-6c) keeping the other parameters constant. 


\section{Current Trends in Fashion Technology \& Textile Engineering}

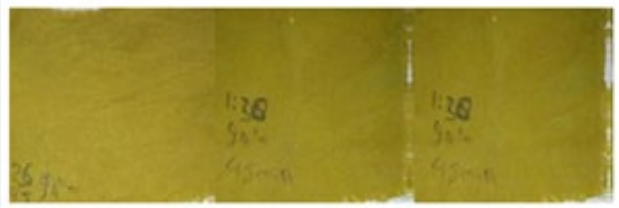

a)

b)

c)

Fabric sample Dyed with MLR of a) 1:25 b) 1:30 c) 1:35

Figure 7: A photo showing cotton fabric samples dyed with peach leaf dye at different MLR, dyed and photographed by the authors, 2019.

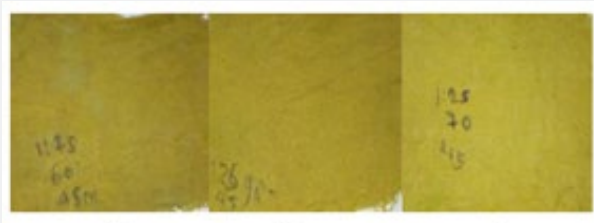

a)

b)

c)

Dyed Fabric sample a) at $60^{\circ} \mathrm{C} \mathrm{b}$ ) at $70^{\circ} \mathrm{C} \mathrm{c}$ ) at $90^{\circ} \mathrm{C}$

Figure 8: A photo showing cotton fabric samples dyed with peach leaf dye at different temperatures, dyed and photographed by the authors, 2019

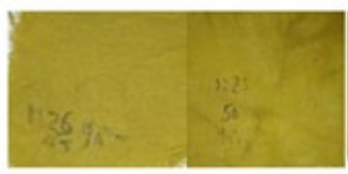

a)

b)

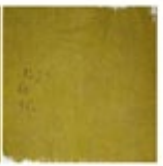

c)

Fabric sample dyed for a) 45 minutes b) dyed fabric sample dyed for 50 minutes c) dyed fabric sample dyed for 60 minutes

Figure 9: A photo showing cotton fabric samples dyed with peach leaf dye for different dyeing times, dyed and photographed by the authors,2019.

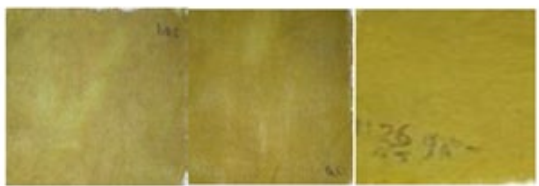

a)

b)

c)

Fabric sample dyed a)In basic media b) In acidic media c) In neutral media

Figure 10: A photo showing cotton fabric samples dyed with peach leaf dye in different dyeing $\mathrm{Ph}$, dyed and photographed by the authors, 2019.

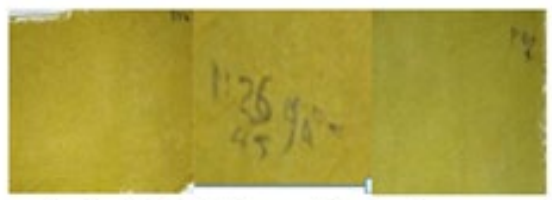

a) Dyed Fabric sample by pre-mordanting b) dyed fabric sample by simultaneous mordanting c) dyed fabric sample by post-mordanting

Figure 11: A photo showing cotton fabric samples dyed with peach leaf dye by different mordanting techniques at neutral $\mathrm{Ph}$, dyed and photographed by the authors, 2019.

The optimum MLR was identified by comparing the shade depth, wash fastness and rubbing fastness of the dyed samples.
Fabric sample- 'a' in Figure 6 Which is dyed with MLR of 1:25 has shown the best wash fastness, color yield and rubbing 
fastness compared to the other dyed samples. Again, three different fabric samples were dyed (Figure 7) at three different dyeing temperatures $(60 \mathrm{oC}, 70 \mathrm{oC}$, and $90 \mathrm{oC})$ keeping the other parameters constant (Figure 8) . Simultaneous mordanting and Dyeing of three (3) fabric samples at neutral $\mathrm{Ph}$ using copper sulfate as mordent for three different dyeing times (45minutes, 50 minutes, and 60minutes) were carried out to compare the quality of dyed samples [31-34]. From the dyed samples; fabric sample dyed for 45 minutes (Figure 9a) found superior quality in terms of wash fastness, shade depth and rubbing fastness. Three fabric samples were dyed at three different $\mathrm{Ph}$, i.e., acidic $\mathrm{Ph}$, basic $\mathrm{Ph}$ and neutral $\mathrm{Ph}$ to evaluate the dyed fabric samples and compare to each other [35-39]. Among the dyed fabric samples at different $\mathrm{Ph}$ (Figure 10), the sample dyed in neutral media exhibited the best-dyed fabric quality. To select an optimum dyeing condition among the different techniques of dyeing and mordanting, three (3) cotton fabrics were dyed by pre, post and simultaneous (Figure 11) mordanting techniques at a neutral Ph.

\section{Evaluation of dyed fabric samples}

\section{Color Measurement and Analysis}

Fabric samples dyed by pre, simultaneous and post mordanting techniques and dyed sample without mordanting at the optimized dyeing conditions (MLR of 1:25 for 45minutes and 900C) characterized for Color strength (K/S) value, reflectance $(\mathrm{R} \%)$ and CIEL*a*b* values as shown in Table 1. In (Figure 12) above the simultaneous mordanting technique has shown higher color strength (K/S) of $190 \%$.

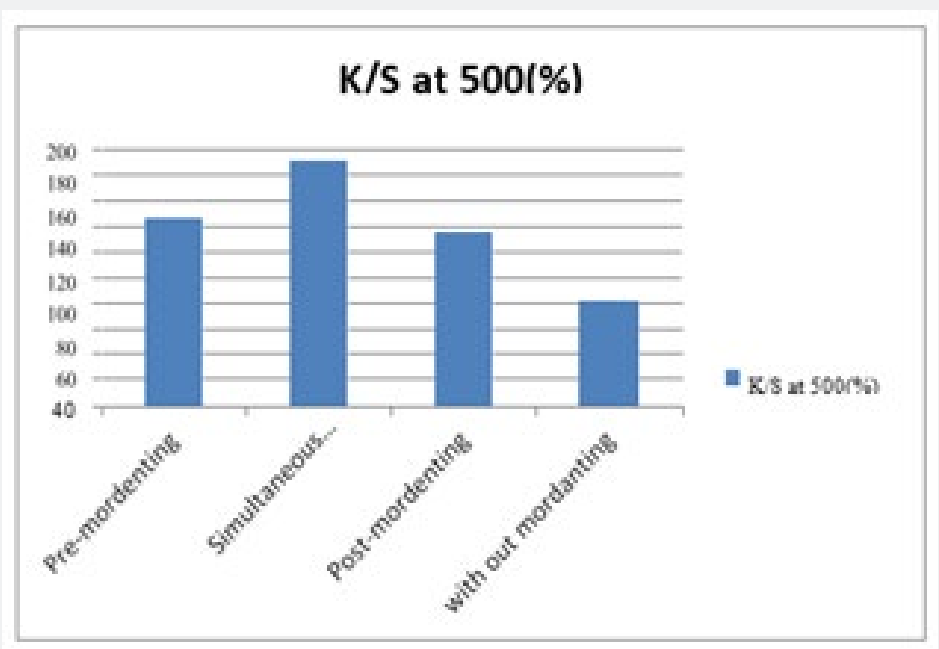

Figure 12: A plot of Color strength (K/S) value of cotton fabric dyed with pre, simultaneous and post mordanting with copper sulfate and without mordent by the optimized dyeing conditions.

Table 1: Color strength $(K / S)$ value, reflectance $(R \%)$ and $C I E L^{*} a^{*} b^{*}$ values of cotton fabric dyed with copper sulfate with the optimized dyeing conditions.

\begin{tabular}{|c|c|c|c|c|c|c|c|c|}
\hline Method of mordanting & K/S at 500(\%) & K/S at 500 & L & A & B & C & H & R (\%) \\
\hline Pre-mordanting & 145.7 & 1.457 & 54.31 & 4.63 & 34.41 & 34.72 & 82.33 & 21.267 \\
\hline Simultaneous mordanting & 190 & 1.9 & 50.29 & 3.83 & 37.18 & 37.38 & 84.11 & 17.743 \\
\hline Post-mordanting & 134.9 & 1.349 & 58.16 & 0.67 & 31.53 & 31.54 & 88.79 & 22.34 \\
\hline
\end{tabular}

\section{Color Fastness testing}

Launder meter was adjusted to $600 \mathrm{C}$ and laundering was carried out for 30 minutes with $15 \mathrm{~g} / \mathrm{l}$ detergent to evaluate the wash fastness of the dyed samples against greyscale to assess the color change. To test rubbing fastness, $10 \mathrm{~cm}$ by $5 \mathrm{~cm}$ dyed fabric sample was rubbed against half bleached fabric 15 times and checked the color is fade on the half-bleached fabric to compare with the standard grading scale. In the above table (Table 2) fabric sample dyed with MLR of 1:25 dyed for 45 minutes at $90 \mathrm{oC}$ in neutral $\mathrm{Ph}$ has super quality than the other dyed samples $[40,41]$. 


\section{Current Trends in Fashion Technology \& Textile Engineering}

Table 2: Fastness to washing and rubbing of peach leaf dyed cotton fabric.

\begin{tabular}{|c|c|c|c|c|c|c|}
\hline \multirow{2}{*}{ Dye concentration in MLR } & \multirow{2}{*}{$\begin{array}{c}\text { Time in } \\
\text { min }\end{array}$} & \multirow{2}{*}{ Temperature } & \multirow{2}{*}{$\mathbf{P h}$} & \multirow{2}{*}{$\begin{array}{c}\text { Color change to } \\
\text { wash }\end{array}$} & \multicolumn{2}{|c|}{ Fastness to Color change } \\
\hline & & & & & Wet rubbing & Dry rubbing \\
\hline $1: 25$ & 45 & 90 & Neutral & 5 & 5-Apr & 5 \\
\hline $1: 30$ & 45 & 90 & Neutral & 5-Apr & $3 / 4$ & 4 \\
\hline $1: 35$ & 45 & 90 & Neutral & $3 / 4$ & 3 & 4 \\
\hline $1: 25$ & 45 & 70 & Neutral & 5-Apr & $3 / 4$ & 4 \\
\hline $1: 25$ & 45 & 60 & Neutral & 4 & $3 / 4$ & 5-Apr \\
\hline $1: 25$ & 60 & 90 & Neutral & 4 & 4 & 5-Apr \\
\hline $1: 25$ & 50 & 90 & Neutral & 5-Apr & $3 / 4$ & 5 \\
\hline $1: 25$ & 45 & 90 & Acidic & 5-Apr & 4 & 5-Apr \\
\hline $1: 25$ & 45 & 90 & Basic & 4 & 3 & 5-Apr \\
\hline
\end{tabular}

\section{Conclusion}

Dyestuff which can dye cotton fabric the required shade depth and color strength can be extracted from the peach leaf at optimized extraction with 1:20 MLR at $80 \mathrm{oC}$ by boiling the mixture of water, peach leaf powder, and methanol for 70 minutes. Peach leaf dye is highly suitable for dyeing cotton fabric by using copper sulfate as a mordent and efficient dyeing of cotton with peach leaf can be carried out using a simultaneous mordanting technique with MLR of 1:25 and dye cotton at $90 \mathrm{oC}$ for 45 minutes in a neutral dye bath. Cotton fabric dyed with peach leaf with the help of copper sulfate has excellent wash fastness and rubbing fastness. These dyes are safe and eco-friendly (Table 3 ). Therefore, the use of peach leaf dyestuff for dyeing of cotton fabric can minimize the health hazards caused using synthetic dyes. As it is for all-natural dyes; predicting the color of peach leaf dyed cotton fabric before dyeing was difficult as the inherent color of the mordents changes the color of the extruded dyestuff.

Table 3: Wash fastness and rubbing fastness of the cotton fabric dyed by pre, simultaneous and post mordanting techniques and without mordent with MLR of 1:25 dyed for 45 minutes at 900 .

\begin{tabular}{|c|c|c|c|}
\hline Fastness properties & Without mordent & pre-mordanting & Simultaneous mordanting \\
\hline Washing & 3-Feb & 5-Apr & 5 \\
\hline Rubbing (wet) & 2 & $5-\mathrm{Apr}$ & $5-\mathrm{Apr}$ \\
\hline Rubbing (dry) & $4-\mathrm{Mar}$ & 5 & 5 \\
\hline
\end{tabular}

\section{References}

1. Iqbal J, Bhatti IA, Adeel S (2008) Effect of UV radiation on dyeing of cotton fabric with extracts of henna leaves. Indian Journal of Fiber \& Textile Research 33: 157-162.

2. Samanta KA, Agarwal P (2009) Application of natural dyes on textiles. Indian Journal of Fiber and Textile Research 34(4): 384-399.

3. Bruna CV, Maria AMM (2013) Azo Dyes: Characterization and ToxicityA review. Textiles and Light Industrial Science and Technology 2 (2): 85-103.

4. Goodarzian H, Ekrami E (2010) Extraction of dye from madder plant (Rubia tinctorium $L$ ) and dyeing of wool. World Applied Sciences Journal 9(4): 436-434.

5. Samanta AK, Konar A (2011) Dyeing of Textiles with Natural Dyes. Natural dyes 30-56.

6. Tassew Alemayehu, Zenebesh Teklemariam (2014) Application of Natural dyes on textile-A Review. International journal of research Granthaalayah 2(2): 61-68.

7. Chattopadhyay SN, Pan NC, Roy AK, Saxena S, Khan A (2013) Development of natural dyed jute fabric with improved color yield and UV protection characteristics. J Text Inst 104(8):808-818.

8. Teklemedhin TB, Gopalakrishnan LH (2018) Environmental Friendly Dyeing of Silk Fabric with Natural Dye Extracted from Cassia singueana Plant. Journal of Textile Science \& Engineering 3(1): 1-6.
9. Acquah SB, Oduro K (2012) Traditional cloth dyeing enterprise at Ntonso: Challenges and opportunities. West African J Applied Ecology 20(1): 25-36.

10. Rungruangkitkrai N, Mongkholrattanasit R (2012) Eco-Friendly of textiles dyeing and printing with natural dyes. RMUTP International Conference: Textiles \& Fashion 1-17.

11. Katarzyna SP, Kowalinski J (2008) Light fastness properties and UV protection factor of naturally dyed linen, hemp and silk. In: Proceedings, flax bast 2008: international conference on flax and other bast PLANTS, Saskatoon, Canada.

12. Saxena S, Raja ASM (2014) Natural Dyes: Sources, Chemistry, Application and Sustainability Issues. Roadmap to Sustainable Textiles and Clothing, Textile Science and Clothing Technology 37-80.

13. Datta S, Uddin MA, Afreen KS, Akter S, Bandyopadhyay A (2013) Assessment of antimicrobial effectiveness of natural dyed fabrics. Bangladesh Journal of Scientific and Industrial Research 48(3): 179184.

14. Prabhu KH, Teli MD (2014) Eco-dyeing using Tamarindus indica L. seed coat tannin as anatural mordant for textiles with antibacterial activity. J Saudi Chem Soc 18(6): 864-872.

15. Renu Singh, Sangita Srivastava (2017) Application of natural dye obtained from peel of black cardamom on silk fabric. International Journal of Home Science 3(2): 94-96. 
16. Samanta AK, Konar A (2011) Dyeing of Textiles with Natural Dyes. Natural dyes 30-56

17. KM FaridulHasan, Zakia Sultana M, Muhammad Abu Taher, Hridam Deb, Mostafizur Rahman Muhammad (2016) Coloration Process \&Parameters for Knit Fabric Dyeing along with Different forms of Dyeing Faults \& Correlated Remedies in Textile Dyeing Industries. IOSR Journal of Polymer and Textile Engineering (IOSR-JPTE) 3(4): 1-23.

18. Ratna, Padhi BS (2012) Pollution due to synthetic dyes toxicity \& carcinogenicity studies and Remediation. International Journal of Environmental Sciences 3(3): 940-955.

19. Zubairu A, Mshelia YM (2015) Effects of Selected Mordants on the Application of Natural Dye from Onion Skin (Allium cepa). Science and Technology 5(2): 26-32.

20. Neha Qumar (2016) Study of nutritional constituents and sensory evaluation of Bakery products prepared from seed and bark Prunus persica (Peach). International Journal of Research - Granthaalayah 4(6): 12-24.

21. Anwar F, Manzoor M, Bukhari IH, Aladedunye F (2014) Physicochemical attribute of fruit seed oils from different varieties of peach and pulm. Journal of Advances in Biology 4(2): 384-392.

22. Meenakshi Nagdeve (2019) Health Benefits \& Nutrition of Peach.

23. Hooda S Herbal (2012) Finishes on cotton and woolen fabrics. Unpublished Doctoral Thesis, CCS Haryana Agricultural University, Hisar.

24. RJ Horvat, GW Chapman (1990) Comparation of Volatile Compounds from peach fruit and leaves. Journal of Agricultural and food Chemistry 38(7): 1442-1444.

25. Sushma Rani, Parveen Punia, Zeba Jamal, Vivek Singh, Sneh Goyal (2016) Antimicrobial property of peach leaves. International Journal of Home Science 2(3): 410-412

26. Zakaria, Muhammad Eanamul Haque Nizam, Muhammad Hasan Al Mamun, Muhammad Abu Yousuf, Ramjan Ali, et al. (2017) Dyeing of S/J Cotton Knit Fabric with Natural Dye Extracts from Green Walnut Shells: Assessment of Mordanting Effect on Fastness Properties. Journal of Textile Science and Technology 3(2): 17-30.

27. Megha Kumari Chhipa, Sandhya Srivastav, Neetee Mehta ( 2017) Study of Dyeing of Cotton Fabric using Peanut Pod Natural Dyes using
Al2So4 CuSo4 and FeSo4 Mordanting Agent. International Journal of Environmental \& Agriculture Research (IJOEAR) 3(2): 36-44.

28. Mishra PK, Singh P, Gupta KK, Tiwari H, Srivastava H (2012) Extraction of natural dye from Dahlia Variabilis using ultrasound. Ind J Fib Text Res 37(1): 83-86.

29. Rahman NAA, Tumin SM, Tajuddin R (2013) Optimization of ultrasonic extraction method of natural dyes from Xylocarpus Moluccensis. Int J Biosci Biochem and Bioinform 3(1): 53-55.

30. Sinha K, Saha PD, Ramya V, Datta S (2012) Improved extraction of natural blue dye from butterfly pea using microwave assisted methodology to reduce the effect of synthetic blue dye. Int J Chem Tech 4(2): $57-65$

31. Sinha K, Chowdhury S, Saha PD, Datta S (2013) Modelling of microwaveassisted extraction of natural dye from seeds of Bixa orellana (Annatto) using response surface methodology(RSM) and artificial neural network (ANN). Ind Crops Prod 41:165-171.

32. Gamma-Decalactone. Pubchem $\mathrm{C} 10 \mathrm{H} 18 \mathrm{O}_{2}$.

33. Gamma-Decalactone Properties. World of chemicals.

34. Body-Evans, Marion. Art Glossary, Lightfastness.

35. Light fastness. Printwiki.

36. IUPAC Gold Book: Chromophore. IPUAC-International union of pure and applied chemistry.

37. Why does ultraviolet light cause colors to fade? Library of congress.

38. Bruce Mac Evoy (2015) Light fastness tests.

39. (2016) Standard Test Methods for Light fastness of colorants used in Artists Materials. ASTM D4303-10 American Standard Test Measure International.

40. (2014) Textiles-Test for color fastness-Part B01: Color fastness to light: Daylight. International Organization for Standardization ISO 105B01:2014

41. Arora J, Prerna Agarwal, Gunjan Gupta (2017) Rainbow of Natural Dyes on Textiles Using Plants Extracts: Sustainable and Eco-Friendly Processes. Green and Sustainable Chemistry 7(1): 35-47.

\section{Your next submission with Juniper Publishers} will reach you the below assets

- Quality Editorial service

- Swift Peer Review

- Reprints availability

- E-prints Service

- Manuscript Podcast for convenient understanding

- Global attainment for your research

- Manuscript accessibility in different formats

( Pdf, E-pub, Full Text, Audio)

- Unceasing customer service

Track the below URL for one-step submission https://juniperpublishers.com/online-submission.php 